Few consultants (17) agreed that the treatment of neurotic patients was "the job of any doctor." Altogether the clinicians were dissatisfied with the existing psychiatric services. These research methods may be criticised but the results confirm popular prejudices about psychiatry and psychiatrists.

Against this background, what are the prospects for psychiatry in the setting of a general hospital ? Most of the psychiatric disorders that present in hospital departments probably require no more special skill than could be provided by a physician and a social worker. Indeed, much of current thinking on the psychosocial assessment of patients who have attempted suicide, ${ }^{8}$ the most common psychiatric condition in hospitals, is in keeping with that view. Subtler sorts of psychiatric distress, however, come less easily to attention in the medical setting. If general physicians are to undertake more responsibility for the psychiatric care of their patients they will have to develop a greater sensitivity to abnormal mental states in the context of physical illness. Meanwhile psychiatry and psychiatrists are set to stay in the medical doldrums. "Liaison" psychiatry ${ }^{9}$ - the subspecialty that provides psychiatric assessments on patients with physical disorders-lacks a coherent theoretical foundation. The conclusion, clearly, is that in the future all hospital doctors should understand and apply the principles and practice of psychological medicine.

1 Shepherd M, Davies B, Culpan RH. Psychiatric illness in the general hospital. Acta Psychiatrica et Neurologica Scandinavica 1960;35:518-25.

${ }^{2}$ Maguire GP, Julier DL, Hawton KE, Bancroft JHJ. Psychiatric morbidity and referral on two general medical wards. $\mathrm{Br}$ Med $\mathcal{F} 1974 ; \mathrm{i}: 268-70$.

${ }^{3}$ Goldberg DP. The detection of psychiatric illness by questionnaire. Institute of Psychiatry, Maudsley Monographs, No 21. London: Oxford University Press, 1972.

4 Goldberg DP, Cooper B, Eastwood MR, Kedward HB, Shepherd M. A standardized psychiatric interview for use in community surveys. Br 7 Prev Soc Med 1970;24:18-23.

${ }^{5}$ Brody DS. Physician recognition of behavioral, psychological, and social aspects of medical care. Arch Intern Med 1980;140:1286-9.

6 Steinberg H, Torem M, Saravay SM. An analysis of physician resistance to psychiatric consultations. Arch Gen Psychiatry 1980;37:1007-12.

${ }^{7}$ Mezey AG, Kellett JM. Reasons against referral to the psychiatrist. Postgrad Med 7 1971;47:315-9.

8 Anonymous. "Overdose-will psychiatrist please see ?" Lancet 1981 ;i: 195-6.

9 Lloyd GG. Whence and whither "liaison" psychiatry. Psychol Med 1980; $10: 11-4$.

\section{Misleading manpower statistics}

On 23 February, BBC television began a new series of the comedy programme Yes Minister with an episode about a new hospital employing some 500 busy managers, administrators, and secretaries but, owing to lack of funds, without a single patient, doctor, or nurse. The episode played on the popular belief that the public services in general, and the health services in particular, are overadministered to the detriment of those whom the services seek to benefit.

Some ammunition to support that belief can be found in the latest report of the Comptroller and Auditor General. In the period 1971-9 total staff numbers in the NHS increased by some 174000 , or $23 \%$. Within that total administrative and clerical staff increased by $46 \%$ and professional and technical staff by $50 \%$. In comparison, medical staff numbers rose by $31 \%$ and nursing and midwifery staff by $25 \%$. Ancillary staff, including catering, domestic, and portering staff, increased by only $3 \%$.
The Comptroller and Auditor General also found wide variations in staffing numbers between regions and areas that could not be explained by differences in the conventional measures of work load, such as bed numbers and relative mortality ratios. For example, in relation to weighted population the South-east Thames region in 1978 was employing $17 \%$ more nurses, $23 \%$ more administrative and clerical staff, and $37 \%$ more ancillary staff than the East Anglian region. Even larger variations were found among hospitals. A study of 18 district general hospitals showed that one employed three times as many catering staff and twice as many porters per 100 beds as others.

On asking the health departments the reasons for such disparities the Comptroller and Auditor General received conflicting replies. On the one hand he was told that attempts were being made to reduce the numbers of certain categories of staff; on the other he was informed by implication that regions and areas with high staffing figures represented standards of provision to which other localities should aspire as their revenue allocations are increased through the reallocation machinery.

Lurking behind this conundrum is a conflicting approach to the evaluation of manpower trends. Judgments about staffing levels that are based on comparisons over time or between areas tend to regard manpower as an absolute measure without too much regard for the service outputs produced by it. The belief that a $46 \%$ increase in administrative and clerical staff between 1971 and 1979 is inherently a bad thing reflects that approach and encourages the view that reductions in certain categories of staff are intrinsically desirable, whatever impact they may have on the balance or efficiency of services.

An assessment that takes account of what people in different categories actually do may lead to different conclusions. The Comptroller and Auditor General found a simple illustration of this: one hospital with a high ratio of catering staff had a centralised catering system that made heavy use of catering staff but saved on nursing time. The Comptroller and Auditor General commented that "comparisons could therefore be complex, lengthy, and uncertain exercises." Precisely so; but until manpower is seen as a means to the wider end of service provision, not as an end in itself, judgments about the supply, distribution, and balance of different categories of staff will remain planted in the quicksands of subjective opinion.

\section{Tardive dyskinesia}

The introduction of effective antipsychotic drugs in the 1950s vastly improved the clinical management of psychotic patients. These drugs rapidly control psychotic symptoms in most cases and prevent recurrences in schizophrenia; but they also often produce unwanted neurological effects early in treatment (dystonias, Parkinsonism, akathisia). Long-term treatment with antipsychotic drugs is also associated with abnormal movements described as tardive dyskinesia. Public disquiet in the United States of America about this adverse drug effect led the American Psychiatric Association to set up a task force to investigate the reaction. Its report provides an excellent account of the condition and contains much sound clinical advice. ${ }^{1}$

Tardive dyskinesia includes orolingual dyskinesia, chorea, athetosis, dystonia, and tics, but not rhythmic tremor. It 